\title{
Determination of Success in the Calculus Sequence Based on Method of Place- ment
}

\section{Mrs. Leslie Bartsch Massey, University of Arkansas}

Leslie Massey is an instructor in the Freshman Engineering Program at the University of Arkansas. She received her BS in Biological Engineering and MS in Environmental Engineering from the University of Arkansas.

\section{Dr. Candace Auburn Rainwater, University of Arkansas}

Dr. Heath Aren Schluterman, University of Arkansas

Dr. Heath Schluterman is a Clinical Assistant Professor and the Associate Director of Academics for the Freshman Engineering Program at the University of Arkansas. Dr. Schluterman completed his B.S. and $\mathrm{Ph} . \mathrm{D}$ in Chemical Engineering at the University of Arkansas.

\section{Mrs. Adrienne Gaines, University of Arkansas}

Adrienne L. Gaines is the Associate Director of Student Services for the Freshman Engineering Program at the University of Arkansas. Gaines completed her B.A. in Management Information Systems at the University of Northern Iowa and M.Ed. in Workforce Development at the University of Arkansas. 


\title{
Determination of Success in the Calculus Sequence Based on Method of Placement
}

\begin{abstract}
As a Freshman Engineering Program, one of our primary concerns is our students' progression through the calculus sequence. The eight-semester degree completion programs (EDCP) for each of nine engineering degrees in the College of Engineering $(\mathrm{CoE})$ require students to begin in Calculus I. As a land grant university, we do not have separate entrance standards to the CoE. The qualifications to enter math courses are set by the Department of Mathematical Sciences (MASC), and the current standards were updated in 2010. The ways in which students may qualify to take Calculus I are through ACT or SAT Math subscores, by completing the optional math placement exam (devised by MASC), completion of prerequisite course (Precalculus, Trigonometry, or Engineering Applications of Mathematics) taken at our university or by transfer, or by earning credit through AP exams.

With these math placement standards, we find that approximately $31 \%$ of CoE students begin in Calculus I while 22\% begin ahead (in Calculus II or higher), 31\% of CoE students begin in Precalculus (one math class behind), and 16\% of CoE students begin in College Algebra (two math classes behind). The goal of this research is to look at the various pathways of how our students qualify for Calculus I and how successful they are in Calculus I and Calculus II the following semester. This should give insight as to whether the updated math placement standards are helping our students be successful in the calculus sequence and thereby helping retention and success in CoE. This information can help shape the Freshman Engineering Program's advising process and our efforts in modifying the Engineering Applications of Mathematics course.
\end{abstract}

\section{Introduction}

The College of Engineering (CoE) at the University of Arkansas established the Freshman Engineering Program (FEP) during the fall of 2007 for the purpose of increasing student retention from the first year to the second year. All incoming freshman students that plan to major in one of nine CoE programs complete a common curriculum during their first year. As a Freshman Engineering Program, one of our primary concerns is our students’ progression through the calculus sequence. The common math core taken by these students includes Calculus I and Calculus II. However, a considerable portion of students enter the $\mathrm{CoE}$ at least one semester behind in math (47\%).

As a land grant university, the University of Arkansas does not have separate entrance standards to the CoE. The qualifications to enter math courses are set by the Department of Mathematical Sciences (MASC), and the current standards were put into place in 2010. Based on these math placement standards, approximately $31 \%$ of CoE students begin in Calculus I, 22\% begin ahead 
(in Calculus II or higher), 31\% of CoE students begin in Precalculus (one math class behind), and $16 \%$ of CoE students begin in College Algebra (two math classes behind).

Previous CoE data has shown that students that begin in Calculus I have a greater retention rate than those who begin in a pre-requisite math course (i.e., Precalculus or College Algebra) (Schluterman et al., 2013). However, not all students are successful in Calculus I during their first semester at the University of Arkansas, and only $76 \%$ of students enrolled in Calculus I during their first semester earned a passing grade of $\mathrm{C}$ or higher. The goal of this research is to look at the various pathways of how our students qualify for Calculus I, and how successful they are in Calculus I and Calculus II. This should give insight as to whether the updated math placement standards are helping our students be successful in the calculus sequence and thereby helping retention and success in the CoE. This information can help shape the FEP's advising process and our efforts in modifying the Engineering Applications of Mathematics course (Schluterman et al., 2013).

\section{Research Questions}

1. Does the way a student places into Calculus I make it more or less likely that they will pass Calculus I?

2. Does the way a student places into Calculus I affect their likelihood of earning a specific letter grade in Calculus I?

3. Does the way a student places into Calculus I make it more or less likely that they will pass Calculus II?

4. Does the way a student places into Calculus I affect their likelihood of earning a specific letter grade in Calculus II?

\section{Background of the University of Arkansas}

In Fall 2015, the institution studied was a land grant, public, university serving 26,754 undergraduate and graduate students, $57 \%$ of which came from within the state. Minimum admission requirements for new freshman applicants was a high school grade point average of 3.0 or higher on a 4.0 scale, and an ACT score of 20 or higher, or the SAT equivalent. The demographic makeup of the students was $51.6 \%$ female, $48.4 \%$ male, and $18.7 \%$ minorities. The majority of students were of traditional college age (91.9\%), full time (87.7\%), and lived on or near campus.

\section{Background of the Freshman Engineering Program}


The FEP, a common first-year experience for new freshman in the CoE, is comprised of two interconnected sub-programs, the Academic Program and the Student Services Program. The Freshman Engineering Academic Program is a two-semester program that includes

- two engineering courses (Introduction to Engineering I and II),

- two mathematics courses (depending on the student's math placement),

- science courses as appropriate based on the student's math placement,

- two English courses (Composition I and II), and

- at least one university core elective.

The Freshman Engineering Student Services Program provides proactive support to FEP students through orientation, academic advising, peer mentoring, and professional development workshops.

\section{Methods of Placement}

The ways in which students may qualify to take Calculus I are by earning credit through AP exams, through ACT or SAT Math subscores, by earning credit for prerequisite courses (i.e., Precalculus, Trigonometry) taken at the University of Arkansas or by transfer, by earning credit for Calculus I taken by transfer, or by completing the optional math placement exam. The minimum qualification for each method of placing into Calculus I is presented in Table 1.

The MASC developed the math placement test with the hopes that all students would take the exam to determine their correct beginning math placement. However, MASC could not require all students to take the exam(s). Therefore, MASC decided to allow students that tested high on the ACT or SAT math exam to automatically place into Calculus I, and the optional math placement exam would allow students to place into higher courses than their ACT/SAT math subscores allow. Students were required to take and pass (score $\geq 80 \%$ ) a Preparedness for Algebra Exam (PALG) and Mastery of Algebra Exam (MALG) before they were allowed to take the Preparedness for Calculus Exam (PCALC). The PCALC covers the following topics:

- Functions and Graphs

- Linear Functions

- Quadratic Functions

- Systems of Linear Equations

- Exponential and Logarithmic Functions

- Right Triangle Trigonometry

- Unit Circle Trigonometry

- Sinusoids and Harmonic Functions 
Table 1. Methods of placing into Calculus I based on minimum qualification criterion, and the percentage of Freshman Engineering (FEP) students (n=1271) enrolled in Calculus I during their first semester that met the minimum criterion.

\begin{tabular}{lcc}
\hline Method of Placement & Minimum Qualification & $\begin{array}{c}\text { Percentage of Students } \\
\text { Meeting Minimum } \\
\text { Qualification }\end{array}$ \\
\hline AP Calculus BC & 3 & $1.57 \%$ \\
AP Calculus AB & 3 & $28.6 \%$ \\
ACT Math subscore & 30 & $48.5 \%$ \\
SAT Math subscore & 680 & $8.73 \%$ \\
College Credit for Calculus I & C or better & $3.22 \%$ \\
College Credit for Precalculus & C or better & $2.68 \%$ \\
College Credit for Trigonometry & C or better & $12.7 \%$ \\
MASC PCALC Exam & $80 \%$ & $15.5 \%$ \\
\hline
\end{tabular}

${ }^{1}$ A student may qualify to take Calculus I by more than one criterion.

\section{Methods of Analysis}

To analyze student success in Calculus I, we considered all FEP students that began their math course of study in Calculus I during the fall semester from 2010-2015 ( $\mathrm{n}=1271)$. To analyze student success in Calculus II, we considered all FEP students that began their math course of study in Calculus I during the fall semester from 2010-2015 and enrolled in Calculus II during their second semester $(n=905)$.

Students received a passing grade in Calculus I and Calculus II by earning a grade of C or higher. Those that did not pass include D, F, \& withdrawals (W). We calculated the percentage of students who passed each math course and statistically compared the passing rate based on the students' placement method. A two-sample t-test between proportions was performed to determine whether there was a significant difference between the percentage of students passing Calculus I through one placement method compared to another placement method. We used an alpha of 0.05 for all analyses.

Because students may have qualified to take Calculus I by more than one method, we chose the following hierarchy to statistically analyze our data by qualification:

1. AP Calculus Credit

- AP Calculus BC credit

- AP Calculus AB credit with no AP Calculus BC credit

\section{Standardized Test Score}

- ACT Math subscore of 30+ and SAT Math subscore of 680+ with no AP math credit 
- ACT Math subscore of 30+ with no AP math credit and no qualifying SAT Math subscore

- SAT Math subscore of 680+ with no AP math credit and no qualifying ACT Math subscore

3. College Course Credit for Calculus I

- College credit for Calculus I with no AP math credit and did not meet ACT/SAT Math subscore requirements

4. College Course Credit for Prerequisite course

- College credit for Precalculus with no AP math credit and did not meet ACT/SAT Math subscore requirements

- College credit for Trigonometry with no AP math credit and did not meet ACT/SAT Math subscore requirements

5. Math Placement Exam Score

- PCALC Exam score of $80 \%+$ with no AP math credit, no prerequites math credit, and did not meet ACT/SAT Math subscore requirements

\section{No Qualifications Met}

- Erroneously enrolled

A small portion of students (4.32\%) enrolled in Calculus I during the fall semester of their freshman year, but they did not meet any of the minimum qualifications. This may happen if a student has received an override to be placed into Calculus I contingent upon scoring a 3 on the $\mathrm{AP}$ Calculus $\mathrm{AB}$ exam. If students fail to achieve the minimum score, they are later administratively dropped from the course, but occasionally a student is overlooked and remains in the course inadvertently.

\section{Results}

Of the 1,271 FEP students that enrolled in Calculus I during their first semester at the University of Arkansas from 2010-2015, 76\% of students earned a passing grade ( $C$ or higher) in the course. The percentage of students earning a passing grade varied by method of placement into Calculus I, and the percentage of students who earned a passing grade in Calculus I is shown in Figure 1. Students who started their freshman year with AP Calculus credit passed Calculus I at a significantly higher rate (91\%) than any other placement method $(\mathrm{P}<0.05)$. This is not surprising since these students had scored high enough on an AP Calculus exam to earn college credit for the course, yet chose to take the course again. Statistically similar passing rates were observed for students who qualified from Math ACT/SAT subscores (78\%) and for students who qualified by passing the PCALC exam (73\%; $\mathrm{P}=0.17)$. Surprisingly, students who earned college credit 
for Calculus I did not do significantly better in Calculus I in their first semester at the University of Arkansas compared to those who only had credit for a prerequisite course ( $\mathrm{P}=0.15)$. Only $56 \%$ of students who earned college credit for Calculus I and $41 \%$ of students who had college credit for either Precalculus or Trigonometry earned a passing grade in Calculus I.

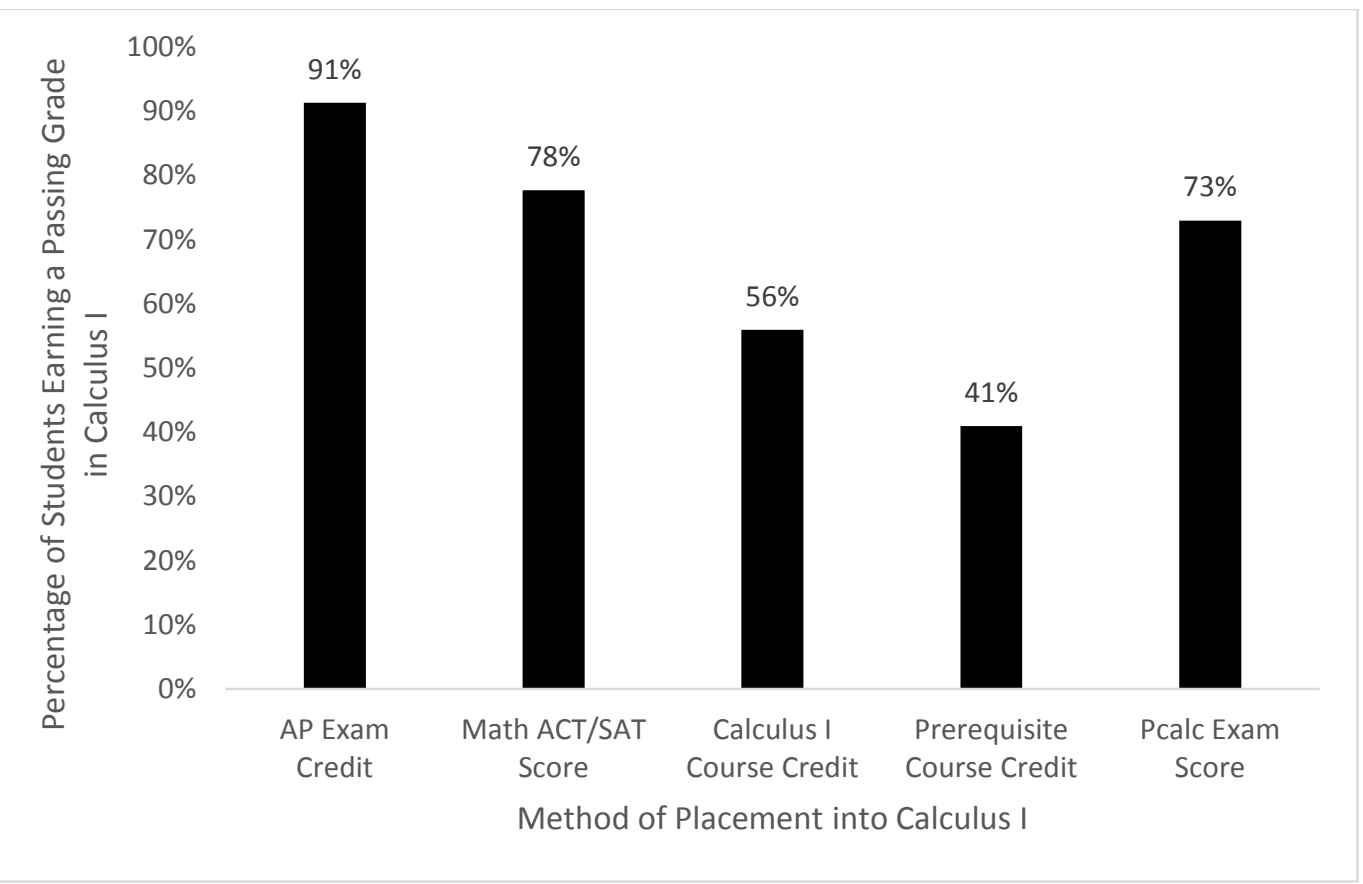

Figure 1. Percentage of FEP students who passed Calculus I during their first semester at the University of Arkansas from 2010-2015. A passing grade was defined as earning a C or better in the course. Data was broken into groups based on how students qualified to take Calculus I during the first semester.

The grade distribution of students earning a passing grade also varied by placement method and is detailed in Table 2. The percentage of students earning an A in the course ranged from $75 \%$ of those with AP Calculus BC credit to only $2 \%$ of students with Trigonometry credit. The majority of students who placed into Calculus I by AP Calculus Credit, standardized test score, PCALC score or were erroneously enrolled in the course earned an A or B in the course. It is difficult to discuss the success of the erroneously enrolled students, but it is most likely that these students have been exposed to Calculus I course material at some point and just did not meet the minimum qualification of AP score or passing grade in transfer course credit.

Students are encouraged to enroll in the appropriate math course at summer orientation (before their fall semester) based upon the qualifications outlined in this paper. However, some students will elect to retake Calculus I, even though they earned credit for the course through AP exams, either out of anticipation of an "easy A" or fear of Calculus II. When students enroll in a course that they have previously mastered, they can easily become bored, quit attending class and neglect to do homework assignments. This, in turn, leads to lower grades in the course and may 
explain the number of students with AP Calculus credit that earned a C or lower in Calculus I. This also highlights the importance of reviewing grade distribution and not just accessing passing or failing rates.

Those who placed into Calculus I because of college credit for Calculus I or a prerequisite course struggled the most in the course. Only 56\% of students with transfer credit for Calculus I earned a passing grade in Calculus I during the fall semester, although these students should have had the same advantage as those who earned credit through AP exams. Students placed by previous course or Calculus I credits also had the highest withdrawal rates (28\%-37\%) compared to other placement methods where only 5\%-11\% withdrew.

Table 2. Grade distribution of freshman engineering students who enrolled in Calculus I $(n=1271)$ during their first semester at the University of Arkansas from 2010-2015.

\begin{tabular}{|c|c|c|c|c|c|c|c|}
\hline \multirow[b]{2}{*}{ Placement Method } & \multirow[b]{2}{*}{$\mathrm{n}$} & \multicolumn{6}{|c|}{$\begin{array}{l}\text { Grade distribution of students enrolled in } \\
\text { Calculus I }\end{array}$} \\
\hline & & $\mathrm{A}$ & $\mathrm{B}$ & $\mathrm{C}$ & $\mathrm{D}$ & $\mathrm{F}$ & $\mathrm{W}^{1}$ \\
\hline \multicolumn{8}{|l|}{ AP Calculus Credit } \\
\hline CalBC Credit & 20 & $75 \%$ & $5 \%$ & $10 \%$ & $5 \%$ & $0 \%$ & $5 \%$ \\
\hline CalAB Credit & 361 & $42 \%$ & $32 \%$ & $18 \%$ & $2 \%$ & $1 \%$ & $5 \%$ \\
\hline \multicolumn{8}{|l|}{ Standardized Test Score } \\
\hline ACT Math Subscore & 393 & $30 \%$ & $30 \%$ & $18 \%$ & $5 \%$ & $5 \%$ & $11 \%$ \\
\hline SAT Math Subscore & 40 & $30 \%$ & $28 \%$ & $18 \%$ & $3 \%$ & $8 \%$ & $15 \%$ \\
\hline ACT and SAT Math Subscores & 35 & $37 \%$ & $29 \%$ & $14 \%$ & $6 \%$ & $9 \%$ & $6 \%$ \\
\hline \multicolumn{8}{|l|}{ College Course Credit } \\
\hline Calculus I Credit & 25 & $12 \%$ & $24 \%$ & $20 \%$ & $8 \%$ & $4 \%$ & $32 \%$ \\
\hline Precalculus Credit & 32 & $9 \%$ & $28 \%$ & $19 \%$ & $6 \%$ & $9 \%$ & $28 \%$ \\
\hline Trigonometry Credit & 117 & $2 \%$ & $13 \%$ & $22 \%$ & $10 \%$ & $16 \%$ & $37 \%$ \\
\hline \multicolumn{8}{|l|}{ Math Placement Exam Score } \\
\hline PCALC Exam score & 190 & $18 \%$ & $35 \%$ & $20 \%$ & $9 \%$ & $6 \%$ & $11 \%$ \\
\hline \multicolumn{8}{|l|}{ No Qualifications Met } \\
\hline Erroneously Enrolled & 58 & $21 \%$ & $41 \%$ & $16 \%$ & $16 \%$ & $2 \%$ & $5 \%$ \\
\hline
\end{tabular}

${ }^{1} \mathrm{~A}$ mark of $\mathrm{W}$ (Withdrawal) is given when a student withdraws from the course after the first 10 days of the semester; $\mathrm{W}$ is not counted in the GPA calculation but does appear on the transcript.

Of the 1,271 FEP students that enrolled in Calculus I during their first semester at the University of Arkansas from 2010-2015, 71\% of students enrolled in Calculus II during the second semester. The remaining students either retook Calculus I or changed their major to something 
outside of the CoE. The majority (76\%) of students who enrolled in Calculus II during the second semester earned a passing grade, and grade earned was less dependent upon Calculus I qualification method. The range of students who earned a passing grade varied from $80 \%$ (those with AP Calculus credit) to 61\% (those with Calculus I course credit). The percentage of students earning a passing grade in Calculus II is shown in Figure 2. Statistically, students who started Calculus I with AP Calculus credit had a significantly higher passing rate in Calculus II than those who started Calculus I with a prerequisite course credit $(\mathrm{P}=0.03)$. Comparisons of all other passing rates between Calculus I placement methods were insignificant $(\mathrm{P}>0.05)$. It is important to note that statistical comparisons with Calculus I course credit were insignificant because of the small sample size $(n=18)$. The low passing rate in Calculus II in the second semester by students who had Calculus I course credit may be attributed to a number of students (7 of 18) who did not pass Calculus I in the fall but advanced to Calculus II based on their previous credit. Only two of these seven passed Calculus II in the spring.

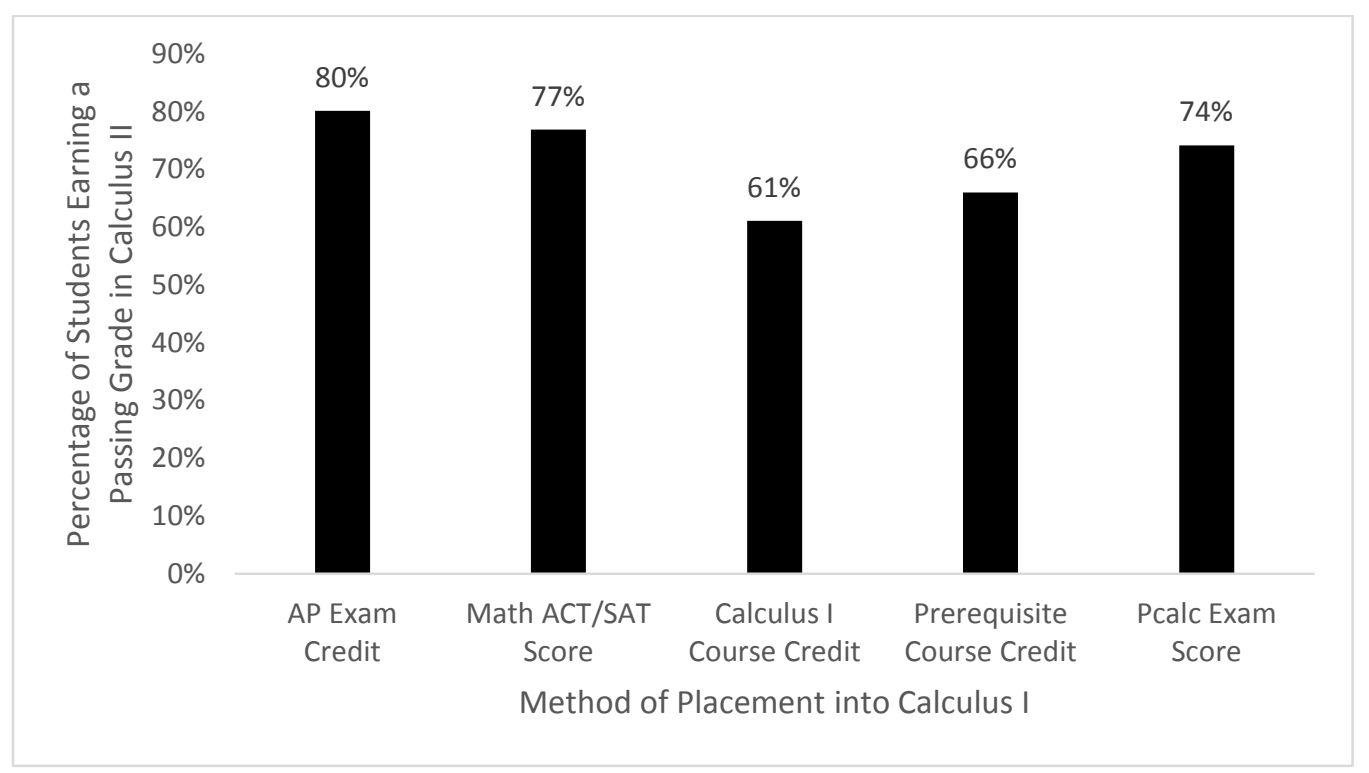

Figure 2. Percentage of FEP students who enrolled in Calculus I during their first semester and passed Calculus II during their second semester at the University of Arkansas from 2010-2015. A passing grade was defined as earning a $\mathrm{C}$ or better in the course. Data was broken into groups based on how students qualified to take Calculus I during the first semester.

While the same percentage of students pass Calculus II as pass Calculus I, fewer students earn a grade of $\mathrm{A}$. The grade distribution of students earning a passing grade was less varied by placement method and is detailed in Table 3. Surprisingly, students who started Calculus I with prerequisite credit for Precalculus had the greatest percentage of students who earned an A in Calculus II (44\%) while only 3\% of students who had Trigonometry credit earned an A. Like with the Calculus I course, the majority of students who placed into Calculus I by AP Calculus Credit, standardized test score, PCALC score or were erroneously enrolled in the course earned an A or B in Calculus II. Conversely, those who placed into Calculus I because of college credit 
for Calculus I or Precalculus did not struggle in Calculus II like they did in Calculus I. The students who qualified for Calculus I through Precalculus transfer credit earned the highest percentage of A's and B's in Calculus II (82\%). This data suggests that taking Calculus I at the University of Arkansas reduces the advantage other students had when they qualified for Calculus I through other means. The students who qualified for Calculus I through Trigonometry transfer credit had the lowest percentage of A's and B's earned in Calculus II (26\%). These students, along with the students who qualified through SAT Math subscores, also had the highest withdrawal rates (35\% and 37\%) compared to other placement methods where 7\%-24\% withdrew.

Table 3. Grade distribution of freshman engineering students in Calculus II ( $n=905)$ during their second semester after enrolling in Calculus I in first semester at the University of Arkansas from 2010-2015.

Grade distribution of students enrolled in Calculus II

Placement Method

AP Calculus Credit

CalBC Credit

CalAB Credit

Standardized Test Score

ACT Math Subscore

SAT Math Subscore

ACT and SAT Math Subscores

College Course Credit

Calculus I Credit

Precalculus Credit

Trigonometry Credit

Math Placement Exam Score

PCALC Exam score

$\begin{array}{ccccccc}11 & 36 \% & 36 \% & 9 \% & 0 \% & 9 \% & 9 \% \\ 316 & 25 \% & 37 \% & 18 \% & 6 \% & 3 \% & 11 \%\end{array}$

$\begin{array}{ccccccc}283 & 28 \% & 34 \% & 18 \% & 4 \% & 4 \% & 13 \% \\ 27 & 26 \% & 15 \% & 7 \% & 11 \% & 4 \% & 37 \% \\ 27 & 26 \% & 33 \% & 19 \% & 11 \% & 4 \% & 7 \%\end{array}$

$\begin{array}{ccccccc}18 & 6 \% & 39 \% & 17 \% & 17 \% & 6 \% & 17 \% \\ 16 & 44 \% & 38 \% & 13 \% & 0 \% & 0 \% & 6 \% \\ 40 & 3 \% & 23 \% & 30 \% & 8 \% & 3 \% & 35 \%\end{array}$

$125 \quad 25 \% \quad 38 \% \quad 12 \% \quad 11 \% \quad 2 \% \quad 13 \%$

No Qualifications Met

Erroneously Enrolled $42 \quad 17 \% \quad 29 \% \quad 14 \% \quad 10 \% \quad 7 \% \quad 24 \%$

${ }^{1} \mathrm{~A}$ mark of $\mathrm{W}$ (Withdrawal) is given when a student withdraws from the course after the first 10 days of the semester; $\mathrm{W}$ is not counted in the GPA calculation but does appear on the transcript. 


\section{Conclusions}

The majority (76\%) of FEP students who take Calculus I their first semester pass the class with a $\mathrm{C}$ or better. We found that the way a student qualifies to take Calculus I does influence the likelihood of them passing the course. The students that qualify to take Calculus I through the AP Calculus BC or AB exams had the highest pass rate, followed by students who qualified through standardized math scores and the math placement exam, and then followed by students who transferred Calculus I, Precalculus, or Trigonometry credit from another college or university. Other studies have shown similar results where AP exam scores and standardized test scores can be used as indicators of success in math courses (e.g., De Urquidi et al., 2015; FoleyPeres and Poirier, 2008). While it is not surprising that students with Calculus I credit from AP exams do well when they retake Calculus I at the University of Arkansas, it is surprising that significantly fewer (50\%) students pass Calculus I at the University of Arkansas if they already have Calculus I credit through dual or transfer credit.

The way a student qualified to take Calculus I also influenced the likelihood of earning a specific grade in Calculus I. Students who qualified through the AP Calculus BC exam had the highest percentage of A's (75\%) while students who transferred in Trigonometry credit earned the lowest percentage (2\%) of A's. Students who qualified to take Calculus I through AP Math credit, standardized test math subscores, the math placement exam, or even those erroneously enrolled mostly earned A's or B's in Calculus I. Those who qualified through dual or transfer Calculus I, Precalculus, or Trigonometry credit earned significantly fewer A's and B's with those who took Trigonometry earning only 15\% A’s and B’s in Calculus I.

Like Calculus I, the majority (76\%) of FEP students who take Calculus II after their first semester pass the class with a $\mathrm{C}$ or better. We found that the way a student qualifies to take Calculus I does not have as great of an influence on the likelihood of them passing Calculus II. The students that qualify to take Calculus I through the AP Calculus BC or AB exams had the highest pass rate, but the rate was only statistically greater than the pass rate for the students who qualified to take Calculus I through Precalculus and Trigonometry courses. Research has suggested that students struggle during their first semester of college because of their differences in expectations between college courses and high school courses (Conley, Aspendgren, Stout \& Veach, 2006), and because college courses typically move at a faster pace (Standards for Success, 2003). It is possible that student success in Calculus II could be because students have had a semester to acclimate to college learning environment and expectations.

The way a student qualified to take Calculus I also influenced the likelihood of earning a specific grade in Calculus II. Students who qualified to take Calculus I through the Precalculus transfer credit had the highest percentage of A's (44\%) while students who transferred in Trigonometry credit earned the lowest percentage (3\%) of A's. Students who qualified to take Calculus I through all methods except Trigonometry transfer credit mostly earned A's or B's in Calculus II. 
The students who were able to pass Calculus I after earning credit for Trigonometry continued to struggle with Calculus II.

The data suggests that students with Calculus I, Precalculus, or Trigonometry dual or transfer credits may not have the skills needed to be successful in a Calculus I course at the University of Arkansas. We may be able to better serve our incoming freshman with dual or transfer credit by advising them to take the math placement exam or to enroll in Precalculus at the University of Arkansas before enrolling in Calculus I.

\section{References}

Conley, D. T., Aspengren, K., Stout, O., \& Veach, D. (2006). College Board Advanced Placement best practices course study report. Eugene, OR: Educational Policy Improvement Center

De Urquidi, K., Verdin, D., Hoffmann, S., Ohland, M.W.: Outcomes of accepting or declining advanced placement calculus credit. In: Frontiers in Education Conference (FIE), pp. 1-6. IEEE (2015)

Foley-Peres, K., \& Poirier, D. (2008). College math assessment: SAT scores vs. college math placement scores. Educational Research Quarterly, 32(2), 41-48.

Schluterman, H. A., \& Schneider, K., \& Gaines, A. L. (2013, June), Implementing an Engineering Applications of Mathematics Course at the University of Arkansas (redacted) and Assessing Retention Impact Paper presented at 2013 ASEE Annual Conference \& Exposition, Atlanta, Georgia. https://peer.asee.org/19721

Standards for Success. (2003). An introduction to work samples and their uses. Eugene, OR: Center for Educational Policy Research, University of Oregon 